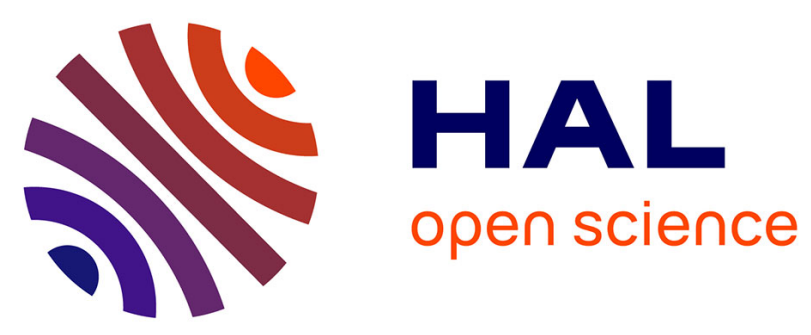

\title{
Prothrombotic markers and early spontaneous recanalization in ST-segment elevation myocardial infarction.
}

Marie-Geneviève Huisse, Emilie Lanoy, Didier Tcheche, Laurent J. Feldman, Annie Bezeaud, Eduardo Anglès-Cano, Murielle Mary-Krause, Dominique de Prost, Marie-Claude Guillin, Ph.Gabriel Steg

\section{To cite this version:}

Marie-Geneviève Huisse, Emilie Lanoy, Didier Tcheche, Laurent J. Feldman, Annie Bezeaud, et al.. Prothrombotic markers and early spontaneous recanalization in ST-segment elevation myocardial infarction.: Thrombin and plasmin generation in early recanalization. Thrombosis and Haemostasis, 2007, 98 (2), pp.420-6. inserm-00160732

\section{HAL Id: inserm-00160732 https://www.hal.inserm.fr/inserm-00160732}

Submitted on 22 Oct 2007

HAL is a multi-disciplinary open access archive for the deposit and dissemination of scientific research documents, whether they are published or not. The documents may come from teaching and research institutions in France or abroad, or from public or private research centers.
L'archive ouverte pluridisciplinaire $\mathbf{H A L}$, est destinée au dépôt et à la diffusion de documents scientifiques de niveau recherche, publiés ou non, émanant des établissements d'enseignement et de recherche français ou étrangers, des laboratoires publics ou privés. 


\section{HAL author manuscript}

\section{Thrombosis \\ and \\ Haemostasis}

\section{PROTHROMBOTIC MARKERS AND EARLY SPONTANEOUS RECANALIZATION IN ST-SEGMENT ELEVATION MYOCARDIAL INFARCTION}

\begin{tabular}{|c|c|}
\hline Journal: & Thrombosis and Haemostasis \\
\hline Manuscript ID: & TH-06-11-0621.R3 \\
\hline Manuscript Type: & Basic/Clinical Studies: cardiovascular biology and cell signalling \\
\hline $\begin{array}{r}\text { Date Submitted by the } \\
\text { Author: }\end{array}$ & 21-May-2007 \\
\hline Complete List of Authors: & $\begin{array}{l}\text { Huisse, Marie-Genevieve; Hopital Bichat, Haematology<br>lanoy, } \\
\text { emilie; INSERM U720<br>Tchetche, didier; Hopital Bichat, } \\
\text { Cardiology<br>Feldman, Laurent; Hopital Bichat, } \\
\text { Cardiology<br>bezeaud, annie; INSERM U698<br>Angles-Cano, } \\
\text { Eduardo; INSERM U698<br>mary-Krause, Murielle; INSERM } \\
\text { U720<br>de Prost, Dominique; INSERM U698<br>Guillin, Marie- } \\
\text { Claude; Hopital Bichat, Haematology; INSERM U698<br>Steg, Ph. } \\
\text { Gabriel; Hopital bichat, Cardiology }\end{array}$ \\
\hline Keywords: & $\begin{array}{l}\text { Thrombin, Tissue factor / factor VII, Microparticles, Acute } \\
\text { myocardial infarction, Risk factors }\end{array}$ \\
\hline
\end{tabular}

\section{S) Scholarone"




\section{PROTHROMBOTIC MARKERS AND EARLY SPONTANEOUS}

\section{RECANALIZATION IN ST-SEGMENT ELEVATION MYOCARDIAL INFARCTION}

Marie-Geneviève Huisse ${ }^{1,4,5}$, Emilie Lanoy ${ }^{3,6}$, Didier Tcheche ${ }^{2}$, Laurent J.Feldman ${ }^{2,5}$, Annie Bezeaud $^{4,5}$, Eduardo Anglès-Cano ${ }^{5}$, Murielle Mary-Krause ${ }^{3,6}$, Dominique de Prost ${ }^{4,5}$, MarieClaude Guillin ${ }^{1,4,5}$, Ph.Gabriel Steg ${ }^{2,5}$.

AP-HP, Hôpital Bichat, Departments of ${ }^{1}$ Haematology and ${ }^{2}$ Cardiology, ${ }^{4}$ CIB PhenoGen ; ${ }^{5}$ INSERM U698 and ${ }^{3}$ U720 ; University Paris7-Denis Diderot, ${ }^{6}$ University Pierre et Marie Curie-Paris 6, Paris, France,

Correspondance to: Dr Marie-Geneviève HUISSE

Service d'Hématologie, Hopital Bichat

46 rue Henri Huchard, 75018, Paris, France

Tel 33.1.40.25.85.21

Fax 33.1.40.25.88.53

e-mail marie-genevieve.huisse@bch.aphp.fr

Running Title: Thrombin and Plasmin Generation in early Recanalization

Financial support: This work was supported by funds from Fondation de France.

Additional support was provided by Diagnostica Stago. 


\section{Abstract}

We tested the hypothesis that selected prothrombotic biomarkers might be associated with early spontaneous coronary recanalization in patients with ST-segment elevation acute myocardial infarction (STEMI).

We prospectively enrolled 123 patients with STEMI including 53 patients with spontaneous coronary recanalization (Cases) and 70 patients with persistent occlusion (Controls) at the time of emergent coronary angiography and before angioplasty. All had received aspirin and heparin. Blood samples were collected immediately before angioplasty to measure soluble Pselectin, circulating microparticles originating from platelets (PMPs), granulocytes (GMPs), endothelial cells (EMPs); tissue factor-associated MP (TF-MP); soluble platelet glycoprotein $\mathrm{V}(\mathrm{sGPV})$ and prothrombin $\mathrm{F} 1+2$; tissue plasminogen activator (tPA), plasminogen activator inhibitor (PAI-1) and plasmin-antiplasmin (PAP). A sub-group of 70 patients (35 cases, 35 controls) was available for flow cytometry analysis of platelet P-selectin and activated GPIIbIIIa. Baseline clinical characteristics did not differ between groups except for more frequent hypertension and dyslipidemia in Controls. Platelet activation markers and PMP did not differ between the two groups. Controls had higher numbers of EMPs and GMPs compared to Cases, but the difference was no longer significant when corrected for risks factors. Controls differed from Cases by higher plasma levels of sGPV [64 (47-84) ng/ml vs 53 (44-63) ng/ml] and PAP [114(65-225) ng/ml vs 88 (51-147) ng/ml]. The difference persisted after adjustment for risks factors $(p=0.031$ and 0.037 , respectively). Persistent occlusion of the infarct related artery is associated with some markers related to higher thrombin (sGPV) and plasmin (PAP) production but is not associated with markers of platelet activation . 
KEYWORDS: myocardial infarction, thrombin, soluble Glycoprotein V, endothelial injury, plasmin-antiplasmin, .

\section{Introduction}

Acute myocardial infarction (AMI) results from the disruption of unstable atheromatous plaques exposing thrombogenic material to blood flow and initiating the 
formation of an occluding arterial thrombus. Platelet activation is triggered by contact with collagen in the extracellular matrix of the plaque, while tissue factor produced by macrophages and smooth muscle cells induces thrombin formation (1). Thrombin amplifies the activation of platelets and converts fibrinogen to fibrin, yielding the characteristic arterial thrombus formed of platelets entrapped in fibrin. Furthermore, microparticles (MPs) resulting from cell activation/apoptosis within the atheromatous plaques (2) contribute to plaque thrombogenicity and may disseminate blood-borne tissue factor activity and procoagulant phospholipids upon plaque rupture (3). Natural fibrinolytic mechanisms (plasminogen activators tPA and UPA) contribute to the dissolution of arterial thrombi. However, high levels of the plasminogen activator inhibitor PAI-1 (associated with several genetic or environmental factors) limit the efficacy of spontaneous fibrinolysis and this factor has been recognized to contribute to cardiovascular risk (4).

Primary percutaneous coronary intervention (PCI) is now established as the reference therapy for the management of ST segment elevation AMI (5). Before PCI, approximately 15$18 \%$ of patients present with angiographically proven spontaneous patency of the infarct artery. These patients have less myocardial damage and a better outcome than patients with occluded arteries $(6,7)$. In the present prospective study, we sought to determine whether patients with spontaneous recanalization of the infarct related artery differ from patients with persistent occlusion at the time of initial angiography, before PCI, in terms of selected biomarkers of cell stimulation, coagulation and/or fibrinolysis activation. This analysis may provide insight into the optimal pathways for improving current pharmacologic therapies designed to recanalize infarct arteries.

\section{METHODS}

\section{Study design}


We undertook a prospective case-control study comparing patients who presented with patent artery at the time of emergency coronary angiography (cases) and patients with occluded artery (controls).

\section{Study patients:}

\section{Inclusion and exclusion criteria}

Patients were eligible for inclusion if they were between 18-80 year old, with symptoms of acute coronary syndrome within the past 12 hours, ST-segment elevation of greater than $1 \mathrm{~mm}$ on their electrocardiogram and creatine kinase twice the upper limit of normal. Patients were excluded if they presented with life-threatening arrythmia, hemodynamic instability or shock or if they had received within 30 days (including the present episode), thrombolytics, GpIIb/IIIa receptor blockers, ticlopidine or clopidogrel, or had undergone angioplasty in the preceding 6 months. From October 2000 to December 2003, we enrolled a total of 123 patients who were triaged to primary percutaneous transluminal coronary angioplasty (PTCA). Patients were transported promptly to the catheterization laboratory and underwent immediate coronary angiography. Flow was assessed at the first contrast injection via the guiding catheter before any wire crossing. All patients had received sublingual or IV nitroglycerin.

\section{Definition of Cases and Controls}

Coronary flow was evaluated quantitatively according to the Thrombolysis In Myocardial Infarction (TIMI) grading system (8). Fifty three patients had a grade TIMI 2-3 and constituted the cases whereas 70 patients had a grade TIMI $0-1$ and constituted the controls. All the patients had received 250 to $500 \mathrm{mg}$ aspirin and $5000 \mathrm{UI}$ of unfractionated heparin before blood collection and angiography. The vast majority received abciximab just before angiography but after blood collection was performed (Table I) The protocol was 
approved by the local Ethics Committee. Written informed consent was obtained from all patients.

\section{Healthy volunteers}

Normal reference values for each prothrombotic markers was determined in 24 healthy volunteers 24-65 year old (median 45), 12 females and 12 males, free of known cardiovascular risks factors. Reference values for plasmin-antiplasmin complexes were determined by one of the co-authors (EAC) in a large cohort including 125 healthy volunteers 21-80 year old ( median 52) comprising 56 females and 69 males. All these individuals have given their informed consent.

\section{Blood sampling and processing:}

Venous peripheral blood was collected from all patients on admission, just before angiography and treatment with abciximab. Blood was drawn in evacuated tubes (Vacutainer ${ }^{\circledR}$, Becton-Dickinson) containing 0.129 M trisodium citrate (1 vol / 9 vol blood), for all assays but plasma soluble GPV (sGPV) measurement (tubes contained CTAD: 0.109M sodium citrate, citric acid, theophylline, adenosine, and dipyridamole) and fibrinolysis parameters analysis (tubes contained CTAD, $100 \mathrm{nM}$ PPACK and $10 \mathrm{UI} / \mathrm{ml}$ aprotinin). Blood was centrifuged within one hour either at $2,500 \mathrm{~g}$ for 20 minutes at $14^{\circ} \mathrm{C}$ for plasma proteins assays or at $1,500 \mathrm{~g}$ for 20 minutes at $20^{\circ} \mathrm{C}$ for microparticles (MPs) isolation. Plasma was kept frozen at $-80^{\circ} \mathrm{C}$ until analysis.

\section{Whole blood platelet activation markers:}

Platelet surface P-Selectin (CD62P, Immunotech, Le Pont-de-Chaix, France) and

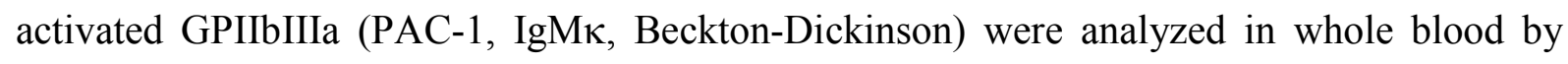
flow cytometry within two hours of blood collection. Preliminary experiments demonstrated 
that these parameters were stable up to two hours after blood collection which limited the flow cytometry study to a sub-group of 35 TIMI 2-3 patients and 35 TIMI 0-1 patients corresponding to patients included when flow cytometry could be rapidly performed. Whole blood samples $(5 \mu 1)$ diluted 1:10 in PBS were incubated with saturating concentrations of fluorescein-conjugated antibodies CD62P, PAC-1 or isotype-matched controls for 30 minutes in the dark and after addition of $1 \mathrm{ml}$ PBS, immediately analyzed by flow cytometry. Percentage of positive platelets were determined as compared to isotype-matched controls. Normal values were less than $2 \%$ for each marker.

\section{Microparticles (MPs) isolation and characterization:}

Microparticles were isolated according to Nieuwland et al (9) and analyzed in a Coulter Epics XL ${ }^{\mathrm{TM}}$ with Expo 32 software (Beckman Coulter). In brief, MPs were extracted from plasma within 2 months of storage at $-80^{\circ} \mathrm{C}$ by centrifugation at $18000 \mathrm{~g}$ for $20 \mathrm{~min}$ at RT, the pellet being washed once in working buffer (WB:10 mM Hepes pH 7.35, $136 \mathrm{mM}, 5$ $\mathrm{mM} \mathrm{KCl}, 2 \mathrm{mM} \mathrm{MgCl2}$ ) containing either $5 \mathrm{mM}$ EDTA (first washing) or no EDTA (for the second washing). The pellet was finally resuspended in WB and directly analyzed by flow cytometry. Extracted MPs $(5 \mu \mathrm{l})$ were incubated for $30 \mathrm{~min}$ in the dark with $45 \mu \mathrm{WB}$ containing $2 \mathrm{mM} \mathrm{CaCl} 2$ and $5 \mu \mathrm{l}$ fluorochrome-conjugated probes, consisting of fluoresceinisothiocyanate (FITC)-annexin V (Immunotech ) and phycoerythrin(PE)-conjugated specific monoclonal antibodies (MoAbs). MoAbs included anti-CD15 (Lewis ${ }^{\mathrm{x}}$, clone 80175, IgM), anti-CD41(GPIIb, clone P2, IgG1), anti-CD106 (VCAM1, clone 5110 C9, IgG1) or isotype controls IgG1 (MOPC21) or IgM (G155-228) (from Immunotech, and PharMingen, San José, CA). Normal values [median(IQR)] of annexinV-positive MPs (total MPs) in 24 normal healthy adult volunteers were $365(281-596) / \mu 1$, originating from platelets (PMPs: 87\%), granulocytes (GMPs: 5\%) and endothelial cells (EMPs: 1.5\%). 


\section{Microparticle-linked tissue factor activity.}

Tissue factor (TF) activity associated to MPs (TF-MP) was determined through the ability of MPs to promote the activation of F X by F VIIa, as described by Key et al (10). In brief, the MPs suspension was mixed with $1 \mathrm{nM}$ recombinant FVIIa (gift from Novo Nordisk, Måløv, Denmark) and 250 nM human FX (Enzyme Research Laboratory, South Bend, IN, USA). After 3 minutes incubation at $37^{\circ} \mathrm{C}$, normal plasma containing $12.5 \mu \mathrm{M}$ phospholipids (20\% phosphatidyl-serine / $80 \%$ phosphatidyl-choline) was added and the clotting time was recorded after addition of $5 \mathrm{mM} \mathrm{CaCl}_{2}$. A standard curve was constructed using relipidated human recombinant TF (American Diagnostica, Greenwich, CT, USA), and results were expressed as $\mathrm{pg} / \mathrm{ml}$ of TF-MP. The specificity of the assay was ascertained by the use of inactivated FVIIa (VIIai, Novo Nordisk,) or a blocking anti-TF MoAb (American Diagnostica) which both completely abolished FXa generation in presence of TF. Normal values [median (IQR)] established in 20 healthy adult volunteers were 35.5 (29-50) pg/ml.

\section{Soluble P-selectin (sPselectin), soluble GPV (sGPV) and Prothrombin fragment} $1+2\left(F_{1+2}\right)$

Plasma levels of sPselectin, sGPV and $\mathrm{F}_{1+2}$ were measured using enzyme-linked immunosorbent assays (ELISA) (sPselectin, R\&D systems Europe, Lille; sGPV, Serbio, Gennevilliers, France and Enzygnost F 1+2, Dade-Behring, Marburg, Germany, respectively). Normal values for plasma sGPV [median (IQR)] were $25.1(14.8$ - 39.9) ng/ml, very similar to the values recently reported in 300 healthy blood donors (11). Normal values indicated by the manufacturer for $\mathrm{F}_{1+2}$ (median and 5th to 95 th percentile) was 115 (69-229) pmol/L.

\section{Biomarkers of fibrinolysis.}


The mass concentrations of tPA and PAI-1 were measured by ELISA using commercially available reagents from Serbio, France. Plasmin- $\alpha 2$ antiplasmin complexes (PAP) were measured using a local ELISA, using specific antibodies as described by Montes et al (12). Normal values [median (IQR)] established from 125 healthy controls were 24.8 $(7.3-35.4) \mathrm{ng} / \mathrm{ml}$.

\section{Statistical analysis}

Continuous variables were expressed as median and interquartile range (IQR), and distributions of qualitative variables were presented with number of patients and percentages. All STEMI patients were included in the analyses (except for platelet P-selectin and activated GpIIb-IIIa which were available in 35 cases and 35 controls). We first tested the relation between the baseline characteristics and the status of the patients: case (i.e spontaneous coronary recanalization) or control (persistent occlusion) in an univariate analysis with the Mann-Whitney test (continuous variables), Chi square test or Fischer exact test as appropriate (qualitative variable).

When biological markers associated with the case versus control status with a $p$ value $\leq 0.20$ in the univariate analysis, they were included simultaneously in a multivariate logistic regression model adjusted on the known coronary risk factors (sex, age, smoking status, hypertension, diabetes mellitus, dyslidemia, anterior MI, delay of revascularization) to evaluate their specific effects. The presence of an interaction between selected biological markers and each of the clinical variables, was also tested in the logistic regression model. All analyses were performed with SPSS statistical software version 11.0 (SPSS Inc., Illinois, Chicago).

A Spearman correlation was computed between biological variables and TF activity. 


\section{RESULTS}

\section{Patients characteristics}

Among the 123 patients enrolled in this prospective study, 53 achieved TIMI 2 to 3 flow (15 TIMI 2 and 38 TIMI 3 flow) and 70 had TIMI 0-1 flow on baseline (preintervention) coronary angiography. Patients with TIMI grade 2 patency did not differ from patients with TIMI 3 flow in terms of biomarkers and the data were therefore pooled together (TIMI 2-3) for comparison with TIMI 0-1 patients. Killip class I was not different between groups $(88.7 \% \vee 91.4 \%$ respectively in cases $v$ controls $)$, as well as Killip class II $(11.3 \% \vee$ $8.6 \%$ in cases $v$ controls). Systolic (SBP) and Diastolic Blood pressure (DBP) did not differ either between groups [125(113-152) mmHg, median(IQR) $\vee 128(112-145)]$ and [76(69-90) mmHg $v 75(68-90)]$ in cases $v$ controls respectively. The baseline characteristics are listed in Table 1 and were similar between groups, with the exception of dyslipidemia and hypertension, which were less frequent in patients with TIMI 2-3 flow (spontaneous recanalization) than in TIMI 0-1 patients (occluded artery). The time delay from symptoms onset and recanalization (spontaneous or instrumental) did not differ between the two groups.

\section{Cell activation markers.}

As previously observed by others (13), platelet surface expression of P-selectin and activated GPIIb/IIIa was increased in patients compared to healthy controls. However, no significant difference was observed between TIMI 0-1 and 2-3 patients (Table 2). Soluble Pselectin was not different between groups, 42 (31.9-54.2) ng/ml, median (IQR) and 40 (33.349.2) ng/ml in TIMI 0-1 and TIMI 2-3 respectively. Likewise, the platelet-derived MPs ( PMPs) were not different in the two groups of patients (Table 3). In contrast, the numbers of both GMPs and EMPs were significantly lower in patients with patent infarct arteries compared to patients with occluded vessels (Table $3, \mathrm{p}=0.021$ and 0.002 , respectively). The 
difference disappeared after adjustment for baseline risk factors. EMPs in TIMI 2-3 patients correlated with SBP $(r=0.307, \mathrm{p}=0.038)$.

\section{Tissue factor.}

Tissue factor activity associated to MPs (TF-MP) did not differ from normal values in TIMI 2-3 patients, but was significantly increased in TIMI 0-1 patients compared to healthy controls $(\mathrm{p}=0.0012)$. However, although levels of TF-MP tended to be lower in patients with patent vs occluded vessels (Table 3), the difference did not reach significance. TF-MP activity correlated with PMPs numbers $(\mathrm{r}=0.287, \mathrm{p}=0.0012)$.

\section{Prothrombin $\mathrm{F}_{1+2}$ and sGPV}

Plasma levels of prothrombin $\mathrm{F}_{1+2}$ were not significantly different between the two patients' groups [136 (60-211) pM/1 and 151 (57-246) pM/1, median (IQR), for TIMI 2-3 and TIMI 0-1 patients, respectively]. We observed a negative correlation between $\mathrm{F}_{1+2}$ levels and anti-Xa activity $(\mathrm{r}=-0.254, \mathrm{p}=0.0052)$.

As previously reported by others $(14,15)$, increased plasma levels of sGPV were observed in our patients, reflecting the important role of platelet activation by thrombin in the acute phase of myocardial infarction. Moreover, sGPV was significantly $(p=0.031)$ lower in TIMI 2-3 patients [53 (44-63) ng/ml] compared to TIMI 0-1 patients [64 (47-84) ng/ml] (fig. 1). The difference persisted after adjustment for risk factors $(p=0.002)$. A weak correlation was observed between sGPV and TF-MP $(r=0.293, p=0.031)$.

\section{Biomarkers of fibrinolysis.}

Plasma levels of tPA antigen were significantly ( $\mathrm{p}=0.011)$ lower in TIMI 2-3 [7 (611) $\mathrm{ng} / \mathrm{ml}]$ than in TIMI 0-1 patients $[10(7-13) \mathrm{ng} / \mathrm{ml}]$. The difference disappeared after 
adjustment for cardiovascular risks factors $(\mathrm{p}=0.303)$. Plasma levels of PAI-1 were similar in TIMI 2-3 patients [22 (11-44) ng/ml ] and TIMI 0-1 patients [22 (12-45) ng/ml]. Plasma levels of PAP complexes were increased in the two groups of patients (fig.2), but significantly lower in TIMI 2-3 patients [88 (51-147) ng/ml] compared to TIMI 0-1 patients [114 (65-225) $\mathrm{ng} / \mathrm{ml}](\mathrm{p}=0.041)$. The difference persisted after adjustment for risk factors $(p=0.037)$ (fig.2) .

\section{DISCUSSION}

Our prospective study aimed to use spontaneous recanalization of the infarct vessel (in patients who received standardized antithrombotic therapy with aspirin and unfractionated heparin) as a paradigm for antithrombotic therapy in STEMI. Investigating differences in circulating markers of platelet activation, tissue factor expression, thrombin generation and fibrinolysis may be valuable to guide selection of additional antithrombotic therapy. The main result of the present analysis is that there are little differences between patients with occluded versus patent vessels in STEMI with respect to markers of platelet activation, except sGPV. In contrast, significant differences were observed in terms of leukocytes and endothelial cells activation. However, these differences disappear after adjustment on risk factors, indicating that the latter are causal. In addition, PAP and tPA levels were lower, paradoxically, in patients with patent versus those with occluded vessels.

Platelet-dependent thrombosis is known to play a critical role in patency and recanalization of the infarct artery in acute myocardial infarction. Yet our study failed to show differences in terms of platelet activation (platelet surface P-selectin and activated GPIIb-IIIa, or PMPs) between patients with patent versus occluded vessels. In contrast, Yip et al (13) have recently showed that platelet surface P-selectin was independently associated with the extent of myocardial necrosis in patients with AMI. We cannot exclude that antithrombotic treatment (aspirin + heparin) already introduced at the time of blood sampling in the present 
study has masked potential differences in the extent of platelet activation between the two groups of patients. Previous observations have shown that unfractionated heparin decreases levels of circulating P-selectin and platelet activation in vivo (16). Aspirin influences Pselectin expression on platelets and inhibits baseline reactivity in patients with $\operatorname{AMI}(17,18)$. However, it is questionable if this treatment could have influenced PMPs numbers .

As previously described by others $(2,15,19)$, acute myocardial infarction was associated with an increase shedding of MPs originating from endothelial cells (EMP). Interestingly, patients with early spontaneous coronary recanalization exhibited significantly lower numbers of circulating EMPs than those with persistent occlusion. EMPs are also associated with multiple concommittent risk factors, in particular with hypertension $(20,21)$. In the present work and consistent with a previous study (21), we found a correlation between EMPs and SBP, but only in cases. This apparent paradox might indicate that the mechanism(s) involved in EMPs generation in patients with persistent occlusion would be different and probably more complex than in patients with early spontaneous coronary recanalization. We also observed an increase in GMPs in our patients, which was significantly lower in TIMI 2-3 versus TIMI 0-1 patients. The present finding extend previous observations demonstrating the involvement of leukocyte-derived MPs in the thrombus growth (22) and plaque burden (23). The difference in EMPs and GMPs levels was no more significant after adjustment for baseline risk factors, indicating that hypertension and dyslipidemia, which were less prevalent in TIMI 2-3 patients, contribute to the differences in MPs shedding from endothelial cells and leukocytes. EMPs and GMPs constitute reliable hallmarks of vascular injury (24) and inflammatory response, which suggests that an inverse relationship between the severity of vascular and inflammatory cells damage and early spontaneous recanalization is highly probable. Alternatively, MPs can act as diffusible messengers, transporting bioactive 
agents $(25,26)$, and high levels of EMPs and GMPs could contribute to the persistence of the coronary occlusion.

Tissue factor is the initial activator of the blood coagulation pathway that leads to thrombin generation and culminates in the fibrin clot formation. Elevated intra-vascular TF, blood-borne or shedded from ruptured plaque, has been reported in MI $(27,28)$ and MPs contribute at least in part to this activity (2). The correlation between TF activity and PMPs, although weak, may suggest that TF-MP is in part supported by PMPs, probably resulting from multiple fusions and exchanges between leukocyte, endothelial and platelet plasma or MP membranes (29) or resulting from platelet TF synthesis upon activation (30). We found a trend for lower levels of TF-MP in patients with early spontaneous recanalization compared to patients with persistent occlusion. It is unclear whether this merely reflects lack of power of our small study or a true lack of difference. In addition, TF activity on MPs is modulated by its inhibitor TFPI (31), which is susceptible to proteolysis thereby limiting its inhibitory activity $(32,33)$.

A reduced generation of thrombin was also associated with spontaneous coronary reperfusion, as indicated by a lower level of sGPV in TIMI 2-3 patients. However, the causal role of TF-MP in sGPV shedding could not be directly established in the present study since the two markers were weakly correlated.

Platelet GPV is directly cleaved by thrombin during platelet activation and SGPV is an indirect but exquisitely sensitive marker of thrombin presence (34). This study indicates that sGPV represents a more sensitive marker of thrombin-induced platelet activation than PMPs. The increased levels of sGPV in patients with occluded infarct arteries thus suggest increased presence of thrombin compared to patients with patent arteries. However, in contrast to sGPV, prothrombin $\mathrm{F}_{1+2}$ levels were similar in the two groups of patients, all of which were treated with unfractionated heparin. The influence of this treatment is highly suggested by the 
correlation between $\mathrm{F}_{1+2}$ levels and anti-Xa activity as already reported (35). We hypothesize that sGPV, which has a longer half-life than $\mathrm{F}_{1+2}$, represents a better marker of thrombin generation in patients receiving heparin $(34,36)$.

In addition to thrombin, TNF-alpha converting enzyme (TACE or ADAM17), a metalloproteinase that is present in platelets, is capable of cleaving GPV (37) upon platelet activation. The ELISA used for the sGPV assay does not discriminate between both fragments released. Consequently, we cannot eliminate the impact of this mechanism in the shedding process, although its contribution would be improbable since we did not evidence differences in platelet activation between the two groups of patients.

Baseline levels of the fibrinolytic components tPA and PAI-1 are recognized biomarkers linked to the risk of major cardiovascular events (38). Lower levels of tPA may appear paradoxical in recanalized patients. Since the tPA assay measures, to a large extent, inactive tPA/PAI complexes, increased tPA antigen levels may be viewed as a correlate of increased PAI-1 activity (39). Plasma levels of tPA antigen are relatively constant over time while PAI-1 antigen levels fluctuate markedly (39), perhaps explaining why the former is a more sensitive marker than the latter. We hypothesize that lower tPA levels in recanalized patients may be related to less endothelial injury mainly modulated by baseline risk factors. The lower level of PAP observed in TIMI 2-3 patients suggests that less plasmin is generated in recanalized patients at the time of blood sampling, which may be the direct consequence of low levels of fibrin-bound tPA able to transform plasminogen into plasmin. Alternatively, the higher levels of PAP in TIMI 0-1 patients could result from plasminogen activation by uPA as a consequence of the greater granulocyte activation $(40,41)$ observed in this group of patients.

Our results suggest that there may be differences in the arterial lesions and/or the hemostatic system between patients with STEMI: less endothelial injury and granulocyte 
stimulation, lower levels of thrombin and plasmin generation appear to correlate with a greater chance of early recanalization of the infarct vessel in patients receiving heparin, and antiplatelet therapy. In addition, our results also show the impact of classical risk factors on persistent coronary thrombosis. Indeed, in the present study, hypertension and dyslipidemia appeared to play a critical role in differences in markers of cell activation, in accordance with previous observations $(42,21)$. Our results indicate that antithrombotic treatment with molecules active on thrombin generation or activity such as the pentasaccharide (43) or bivalirudin $(44,45)$ might favor spontaneous recanalization and deserve to be tested.

Study Limitations

A potential limit of our study is the selection of cases and controls towards inclusion of the most stable patients. The small size of the study could have also underpowered differences between groups.

Flow cytometry on platelets was performed only in 35 patients in each group which corresponded to patients included during the day-time. It is possible that this selection has introduced a bias in platelet activation markers (46).

\section{Aknowledgements.}

We wish to thank L. Venisse, S. Loyau, C. Bousquet, N. Belgueirma, Y. Baudoin, P. Cornelie for their expert technical assistance. We also wish to thank A. Dauphin for collecting clinical data. 


\section{References}

1- Libby P, Theroux P. Pathophysiology of coronary artery disease. Circulation 2005; 111: 3481-88.

2- Mallat Z, Benamer $\mathrm{H}$, Hugel B, et al. Elevated levels of shed membrane microparticles with procoagulant potential in the peripheral circulating blood of patients with acute coronary syndromes. Circulation 2000; 29: 101, 841-3.

3- Morel O, Toti F, Hugel B, et al. Procoagulant Microparticles. Disrupting the Vascular Homeostasis Equation? Arterioscler Thromb Vasc Biol 2006; 26 : 2594-604.

4- Juhan-Vague I, Alessi MC. PAI-1, obesity, insulin resistance and risk of cardiovascular events. Thromb Haemost 1997; 78: 656-60.

5- Keeley EC, Boura JA, Grines CL. Primary angioplasty versus intravenous thrombolytic therapy for acute myocardial infarction: a quantitative review of 23 randomised trials. Lancet 2003; 361: 13-20.

6- Steg PG, Himbert D, Benamer H, et al. Conservative management of patients with acute myocardial infarction and spontaneous acute patency of the infarct-related artery. Am Heart J 1997; 134: 248-52.

7- Brodie BR, Stuckey TD, Hansen C, et al. Benefit of coronary reperfusion before intervention on outcomes after primary angioplasty for acute myocardial infarction. Am J Cardiol 2000; 85: 13-8.

8- The Thrombolysis in Myocardial Infarction (TIMI) trial. Phase I findings. TIMI Study Group. N Engl J Med 1985; 312: 932-6.

9- Nieuwland R, Berckmans RJ, McGregor S, et al. Cellular origin and procoagulant properties of microparticles in meningococcal sepsis. Blood 2000; 95: 930-5.

10-Key NS, Slungaard A, Dandelet L, et al. Whole blood tissue factor procoagulant activity is elevated in patients with sickle cell disease. Blood 1998; 91: 4216-23. 
11-Aleil B, Meyer N, Wolff V, et al. Plasma glycoprotein V levels in the general population: Normal distribution, associated parameters and implications for clinical studies. Thromb Haemost 2006; 96: 505-511.

12- Montes R, Paramo JA, Angles-Cano E, et al. Development and clinical application of a new ELISA assay to determine plasmin-alpha2-antiplasmin complexes in plasma. $\mathrm{Br}$ J Haematol 1996; 92: 979-85.

13- Yip HK, Chang LT, Sun CK, et al. Platelet activity is a biomarker of cardiac necrosis and predictive of untoward clinical outcomes in patients with acute myocardial infarction undergoing primary coronary stenting. Circ J 2006; 70: 31-36.

14- Aleil B, Mossard JM, Wiesel ML, et al. Increased plasma levels of soluble platelet glycoprotein V in patients with acute myocardial infarction. J Thromb Haemost 2003; 1: 1846-7.

15- Morel O, Hugel B, Jesel L, et al. Circulating procoagulant microparticles and soluble GPV in myocardial infarction treated by primary percutaneous transluminal coronary angioplasty. A possible role for GPIIb-IIIa antagonists. J Thromb Haemost 2004; 2: 1118-26.

16-Pernerstorfer T, Eichler HG, Stohlawetz P, et al. Effects of heparin and aspirin on circulating P-selectin, E-selectin and von Willebrand Factor levels in healthy men. Atherosclerosis. 2001; 155: 389-93.

17-McKenzie ME, Malinin AI, Bell CR, et al. Aspirin inhibits surface glycoprotein IIb/IIIa, P-selectin, CD63, and CD107a receptor expression on human platelets. Blood Coagul Fibrinolysis. 2003; 14: 249-53.

18-Serebruany VL, Gurbel PA, Murugesan SR et al. Depressed plasma platelet-activating factor acetylhydrolase in patients presenting with acute myocardial infarction. Cardiology. 1998; 90:127-30. 
19- Bernal-Mizrachi L, Jy W, Jimenez JJ, et al. High levels of circulating endothelial microparticles in patients with acute coronary syndromes. Am Heart J 2003; 145: 96270.

20- Lip GY, Blann AD, Beevers DG. Prothrombotic factors, endothelial function and left ventricular hypertrophy in isolated systolic hypertension compared with systolicdiastolic hypertension. J Hypertens. 1999;17:1203-7.

21-Preston RA, Jy W, Jimenez JJ, et al. Effects of severe hypertension on endothelial and platelet microparticles. Hypertension 2003; 41: 211-7.

22-Falati S,Liu Q, Gross P, et al. Accumulation of tissue factor into developing thrombi in vivo is dependent upon microparticle P-selectin glycoprotein ligand 1 and platelet P-selectin. J Exp Med. 2003;197:1585-98.

23-Chironi G, Simon A, Hugel B, et al. Circulating leukocyte-derived microparticles predict subclinical atherosclerosis burden in asymptomatic subjects. Arterioscler Thromb Vasc Biol. 2006;26:2775-80.

24- Koga H, Sugiyama S, Kugiyama K, et al. Elevated levels of VE-cadherin-positive endothelial microparticles in patients with type 2 diabetes mellitus and coronary artery disease. J Am Coll Cardiol 2005; 45: 1622-30.

25-Boulanger CM, Scoazec A, Ebrahimian T, et al. Circulating microparticles from patients with myocardial infarction cause endothelial dysfunction. Circulation 2001; 104: $2649-52$.

26-Mesri M, Altieri DC. Leukocyte microparticles stimulate endothelial cell cytokine release and tissue factor induction in a JNK1 signaling pathway. J Biol Chem 1999; 274: $23111-8$.

27-Suefuji H, Ogawa H, Yasue H, et al. Increased plasma tissue factor levels in acute myocardial infarction. Am Heart J 1997; 134: 253-9. 
28- Bonderman D, Teml A, Jakowitsch J, et al. Coronary no-reflow is caused by shedding of active tissue factor from dissected atherosclerotic plaque. Blood $2002 ; 99,2794$ 800.

29- Rauch U, Bonderman D, Bohrmann B, et al. Transfer of tissue factor from leukocytes to platelets is mediated by CD15 and tissue factor. Blood 2000; 96: 170-5.

30- Schwertz H, Tolley ND, Foulks JM, et al. Signal-dependent splicing of tissue factor pre-mRNA modulates the thrombogenicity of human platelets. J Exp Med. 2006; 203: 2433-40.

31-Steppich B, Mattisek C, Sobczyk D, et al. Tissue factor pathway inhibitor on circulating microparticles in acute myocardial infarction. Thromb Haemost 2005; 93 : $35-9$

32-Ott I, Malcouvier V, Schomig A, et al. Proteolysis of tissue factor pathway inhibitor-1 by thrombolysis in acute myocardial infarction. Circulation. 2002; 105: 279-81.

33-Belaaouaj AA, Li A, Wun TC. Matrix metalloproteinases cleave tissue factor pathway inhibitor. Effects on coagulation. J Biol Chem. 2000; 275: 27123-8

34- Ravanat C, Freund M, Mangin P, et al. GPV is a marker of in vivo platelet activation-study in a rat thrombosis model. Thromb Haemost 2000; 83: 327-33.

35-Kottke-Marchant K, Bahit MC, Granger CB, et al. Effect of hirudin vs_heparin on haemostatic activity in patients with acute coronary syndromes; the GUSTO-IIb haemostasis substudy. Eur Heart J 2002; 15: 1202-12

36- Tschöpl M, Tsakiris DA, Marbet GA, et al. Role of hemostatic risk factors for restenosis in peripheral arterial occlusive disease after transluminal angioplasty. Arterioscler Thromb Vasc Biol 1997; 17: 3208-14

37- Rabie T, Strehl A, Ludwig A et al. Evidence for a role of ADAM17 (TACE) in the regulation of platelet glycoprotein V. J Biol Chem 2005; 15: 14462-8 
38- Thogersen AM, Jansson JH, Boman K, et al. High plasminogen activator inhibitor and tissue plasminogen activator levels in plasma precede a first acute myocardial infarction in both men and women: evidence for the fibrinolytic system as an independent primary risk factor. Circulation 1998; 98: 2241-7.

39-Ridker PM, Brown NJ, Vaughan DE, et al. Established and emerging plasma biomarkers in the prediction of first atherothrombotic events. Circulation 2004; 109, Suppl 1:IV6-19.

40- Barron HV, Cannon CP, Murphy SA, et al. Association between white blood cell count, epicardial blood flow, myocardial perfusion, and clinical outcomes in the setting of acute myocardial infarction: a thrombolysis in myocardial infarction 10 substudy. Circulation 2000; 102: 2329-34.

41-Kirtane AJ, Bui A, Murphy SA, et al. Association of peripheral neutrophilia with adverse angiographic outcomes in ST-elevation myocardial infarction. Am J Cardiol 2004; 93: 532-6.

42-Sambola A, Osende J, Hathcock J, et al. Role of risk factors in the modulation of tissue factor activity and blood thrombogenicity. Circulation 2003; 107: 973-7.

43-Yusuf S, Mehta SR, Chrolavicius S, et al. OASIS-6 Trial Group. Effects of fondaparinux on mortality and reinfarction in patients with acute ST-segment elevation myocardial infarction: the OASIS-6 randomized trial. JAMA 2006; 295 : 1519-30.

44- Lincoff AM, Bittl JA, Kleiman NS, et al. REPLACE-1 Investigators. Comparison of bivalirudin versus heparin during percutaneous coronary intervention (the Randomized Evaluation of PCI Linking Angiomax to Reduced Clinical Events [REPLACE]-1 trial). Am J Cardiol 2004; 93: 1092-96. 
45-Stone GW, Bertrand M, Colombo A, et al. Acute Catheterization and Urgent Intervention Triage strategY (ACUITY) trial: study design and rationale. Am Heart J 2004; 148: 764-75.

46- De Luca G, Suryapranata H, Ottervanger JP et al. Circadian variation in myocardial perfusion and mortality in patients with ST-segment elevation myocardial infarction treated by primary angioplasty. Am Heart J. 2005; 150: 1185-9. 


\section{Legends to Figures and Tables}

Figure 1.

Soluble GPV (sGPV) in 70 controls (TIMI 0-1, grey bars) and 53 cases (TIMI 2-3, clear bars). P value was calculated after adjustment on baseline cardio-vascular risk factors. In these plots, lines within boxes represent median values, the lower and upper lines of the boxes represent the $25^{\text {th }}$ and $75^{\text {th }}$ percentiles, respectively, and the lower and upper bars outside the boxes represent the $10^{\text {th }}$ and $90^{\text {th }}$ percentiles, respectively.

Figure 2.

Plasmin-antiplasmin (PAP) complexes in 70 controls (TIMI 0-1, grey bars) and 53 cases (TIMI 2-3, clear bars) patients. P value was calculated after adjustment on baseline cardiovascular risk factors. Plots are outlined as in figure 1.

Table 1

Qualitative variables are expressed as number (observed number/total number) and (\%), and quantitative variables are expressed with median and range (minimum-maximum).

Table 2

Platelet P-selectin and activated GpIIb-IIIa (PAC-1) expression as measured by flow cytometry in 35 controls (TIMI 0-1 flow) and 35 cases ( TIMI 2-3 flow). Data are expressed as per cent positive platelets as compared to isotype controls.

Table 3.

Microparticles (MPs) values are expressed as number per $\mu 1$, median (interquartile range, IQR); PMPs: platelet derived MPs; GMPs: granulocyte-derived MPs; EMPs: endothelial 
derived MPs; TF-MP: Tissue factor associated with microparticles. TF-MP activity is expressed as pg/ml, median (IQR).

$\mathrm{P}$ value according to Mann-Whitney U-test. $\mathrm{P} *$ value of logistic regression after correction for risk factors - age, smoking, hypertension, dyslipidemia, diabetes mellitus, anterior location of MI, delay between onset of pain and recanalization .

Table 1. Patients Baseline Characteristics

\begin{tabular}{|c|c|c|c|}
\hline Variables & $\begin{array}{l}\text { TIMI } 2 / 3 \text { patients } \\
\qquad(\mathrm{n}=53)\end{array}$ & $\begin{array}{l}\text { TIMI } 0 / 1 \text { patients } \\
\qquad(\mathrm{n}=70)\end{array}$ & $\mathrm{p}$ value \\
\hline Women & $3 / 53(5.8)$ & $11 / 70(15.7)$ & 0.088 \\
\hline Age (years), median (range) & $53(34-80)$ & $57(29-80)$ & 0.385 \\
\hline Age $>70$ years & $8 / 53(15.1)$ & $11 / 70(15.7)$ & 0.611 \\
\hline Hypertension & $12 / 53(22.6)$ & $30 / 69(43.5)$ & 0.016 \\
\hline Prior or current smoking & $46 / 52(88.5)$ & $54 / 69(78.2)$ & 0.321 \\
\hline Dyslipidemia & $18 / 53(34.0)$ & $36 / 69(52.2)$ & 0.045 \\
\hline Diabetes mellitus & $7 / 53(13.2)$ & $8 / 70(11.4)$ & 0.765 \\
\hline $\begin{array}{l}\text { Delay from symptoms onset to } \\
\text { recanalization (hours), median (range) }\end{array}$ & $3.0(1.3-10.9)$ & $3.5(0.4-9.4)$ & 0.377 \\
\hline $\begin{array}{l}\text { Delay from symptoms onset to } \\
\text { recanalization }>2 \text { hours }\end{array}$ & $47 / 53(88.7)$ & $52 / 63(82.5)$ & 0.352 \\
\hline Anterior myocardial infarction & $22 / 53(41.5)$ & $23 / 70(32.8)$ & 0.324 \\
\hline Abciximab before coronarography & $43 / 53(81.1)$ & $62 / 70(88.6)$ & 0.248 \\
\hline
\end{tabular}


Table 2. Platelet P-selectin and PAC-1 expression by flow cytometry. Per cent positive platelets, median(IQR)

\begin{tabular}{lccc}
\hline & TIMI 0/1 & TIMI 2/3 & $\mathrm{p}$ \\
& $\mathrm{N}=35$ & $\mathrm{~N}=35$ & \\
\hline P-selectin & $3.6(2-6.1)$ & $5.2(1.6-10.3)$ & 0.173 \\
& & & \\
PAC-1 & $12(6-21)$ & $13.2(4-33)$ & 0.411 \\
& & & \\
\hline
\end{tabular}


Table 3 . Microparticles quantification, cellular origin and associated-TF activity in patients with AMI according to their flow grade.

\begin{tabular}{lcccc}
\hline Microparticles & TIMI 0/1 & TIMI 2/3 & $\mathrm{P}$ & $\mathrm{p}^{*}$ \\
& $\mathrm{~N}=70$ & $\mathrm{~N}=53$ & & \\
& & & & \\
\hline Origin & & & & \\
Total MPs & $507(186-738)$ & $312(152-751)$ & 0.331 & 1.000 \\
PMPs & $386(112-677)$ & $251(104-459)$ & 0.126 & 1.000 \\
GMPs & $38(13-112)$ & $27(10-62)$ & 0.021 & 0.995 \\
EMPs & $14(8-26)$ & $11(4-15)$ & 0.002 & 0.991 \\
Activity & & & & \\
TF-MP pg/ml & $72(31-151)$ & $40(22-101)$ & 0.09 & 0.996 \\
& & & & \\
\hline
\end{tabular}


Fig. I

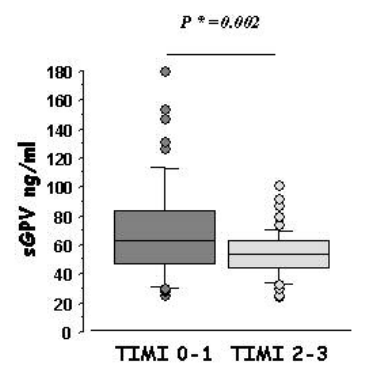

254x190mm (96 x 96 DPI) 


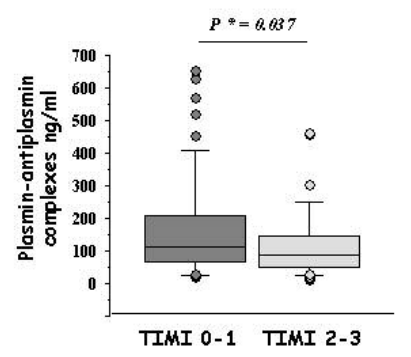

254×190mm (96 x 96 DPI) 